\title{
Groundwater pressure changes and crustal deformation before and after the 2007 and 2014 eruptions of Mt. Ontake
}

\author{
Naoji Koizumi ${ }^{*}$ (i), Tsutomu Sato ${ }^{2}$, Yuichi Kitagawa² and Tadafumi Ochi ${ }^{2}$
}

\begin{abstract}
Volcanic activity generally causes crustal deformation, which sometimes induces groundwater changes, and both of these phenomena are sometimes detected before volcanic eruptions. Therefore, investigations of crustal deformation and groundwater changes can be useful for predicting volcanic eruptions. The Geological Survey of Japan, National Institute of Advanced Industrial Science and Technology, has been observing groundwater pressure at Ohtaki observatory (GOT) since 1998. GOT is about $10 \mathrm{~km}$ southeast of the summit of Mt. Ontake. During this observation period, Mt. Ontake has erupted twice, in 2007 and in 2014. Before the 2007 eruption, the groundwater pressure at GOT clearly dropped, but it did not change before or after the 2014 eruption. These observations are consistent with the crustal deformation observed by Global Navigation Satellite System stations of the Geospatial Information Authority of Japan. The difference between the 2007 and 2014 eruptions can be explained if a relatively large magma intrusion occurred before the 2007 eruption but no or a small magma intrusion before the 2014 eruption.
\end{abstract}

Keywords: Mt. Ontake, Groundwater, Crustal deformation, Volcanic eruption, Magma, Precursor

\section{Background}

Volcanic activity generally causes crustal deformation, which sometimes induces groundwater changes, and both the crustal deformation and the accompanying groundwater changes are sometimes detected before a volcanic eruption or volcano-related seismic activity (e.g., Okada et al. 2000; Sparks 2003; Koizumi et al. 2004). Therefore, investigations of crustal deformation and groundwater changes can be useful for predicting volcanic eruptions.

Mt. Ontake is a volcano situated on the border between Nagano and Gifu prefectures in central Japan (Fig. 1). The first recorded phreatic eruption of Mt. Ontake occurred in 1979, and small phreatic eruptions occurred again in 1991 and 2007 (e.g., Nakamichi et al. 2009; Japan Meteorological Agency 2014). On September 27, 2014, Mt. Ontake produced another, larger phreatic eruption

\footnotetext{
*Correspondence: koizumi.n@ses.usp.ac.jp

${ }^{1}$ School of Environmental Science, The University of Shiga Prefecture,

2500, Hassaka-cho, Hikone-City, Shiga 522-8533, Japan

Full list of author information is available at the end of the article
}

with a volcanic explosivity index (VEI) of 2 (Earthquake Research Institute in the University of Tokyo 2014; Japan Meteorological Agency 2014). The toll of dead and missing was 63 (e.g., Cyranoski 2014). The seismic activities including tremors linked to the 2014 eruption have been deeply analyzed (Kato et al. 2015; Maeda et al. 2015; Ogiso et al. 2015).

In this study, we examined groundwater changes and crustal deformation associated with the 2007 and 2014 eruptions of Mt. Ontake. Those associated with the 2007 eruption were clearly different from those associated with the 2014 eruption. We investigated the reason for this difference and its relationship with the mechanisms of these two eruptions of Mt. Ontake.

\section{Methods}

In 1998, the Geological Survey of Japan, National Institute of Advanced Industrial Science and Technology (AIST), began monitoring groundwater at its Ohtaki observatory (GOT) (Fig. 1; Imanishi et al. 2004), which is about $10 \mathrm{~km}$ southeast of the summit of Mt. Ontake. At the bottom of the borehole, the surrounding rock is 
the Jurassic sedimentary complex of the Mino Belt (Yamada and Wakita 1989). During this observation period, Mt. Ontake has erupted twice, in March 2007 and again in September 2014. At GOT, groundwater pressure is measured with a resolution of about $2 \mathrm{~mm}$ by a gage in a sealed well. The altitude of the well is about $1040 \mathrm{~m}$, and the screen is at $645-663 \mathrm{~m}$ depth. The groundwater pressure at GOT shows clear tidal fluctuations induced by tidal volumetric strain changes, mainly caused by earth tides (Fig. 2). As a result, the volumetric strain at about $650 \mathrm{~m}$ depth (i.e., about $390 \mathrm{~m}$ elevation) can be observed by measuring the groundwater pressure.

To examine crustal deformation, we used daily positional information from four Global Navigation Satellite System (GNSS) stations operated by the Geospatial

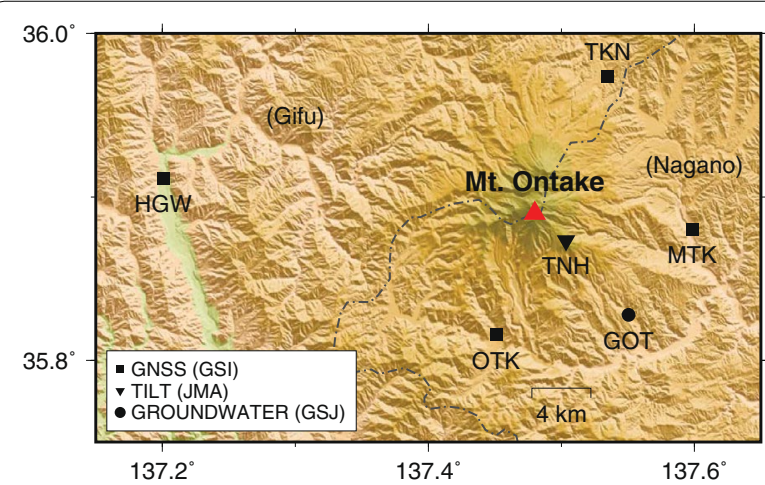

Fig. 1 Topographic map of Mt. Ontake showing the locations of the observation stations. GOT, groundwater observation station of the Geological Survey of Japan, AIST; TNH, tilt station of the Japan Meteorological Agency (JMA); HGW, MTK, OTK, and TKN are GNSS observation stations of the Geospatial Information Authority of Japan (GSI). The background topography is derived from those contained within GSI Digital Elevation Model

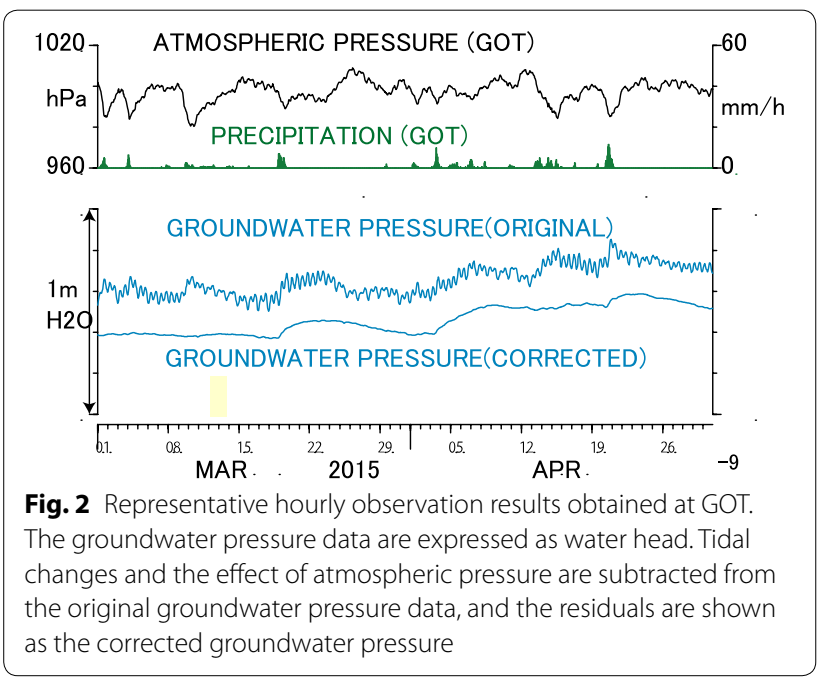

Information Authority of Japan (GSI), TKN, MTK, OTK, and HGW and calculated the baseline distance between pairs of stations. The daily positional data were downloaded from the homepage of GSI (Geospatial Information Authority 2015). We also used tilt data from a tilt station $(\mathrm{TNH})$ operated by the Japan Meteorological Agency.

\section{Results}

The original groundwater pressure data measured at GOT includes diurnal and semidiurnal oscillations caused mainly by earth tides (tidal volumetric strain changes). Atmospheric pressure and precipitation also affect the groundwater pressure. These tidal changes and the effects of atmospheric pressure were estimated and subtracted from the groundwater pressure by using the BAYTAP-G tidal analysis program (Tamura et al. 1991), and the residual values were used as the corrected groundwater pressure (Fig. 2).

The theoretical volumetric strain changes of the $\mathrm{M}_{2}$ and $\mathrm{O}_{1}$ tidal components at GOT calculated by the GOTIC2 program (Matsumoto et al. 2001) are 9.7 and 6.4 nstrain, respectively. We estimated the volumetric strain sensitivity of the groundwater pressure from its tidal changes, which were calculated every 61 days by the BAYTAP-G (Fig. 3). The strain sensitivity to the $\mathrm{O}_{1}$ component is a little larger than the sensitivity to the $\mathrm{M}_{2}$ component. In 2011, we opened the well to sample the groundwater. After that, the strain sensitivities to both components became larger than before. In October 2014, we opened the well again, this time to replace the pressure sensor.

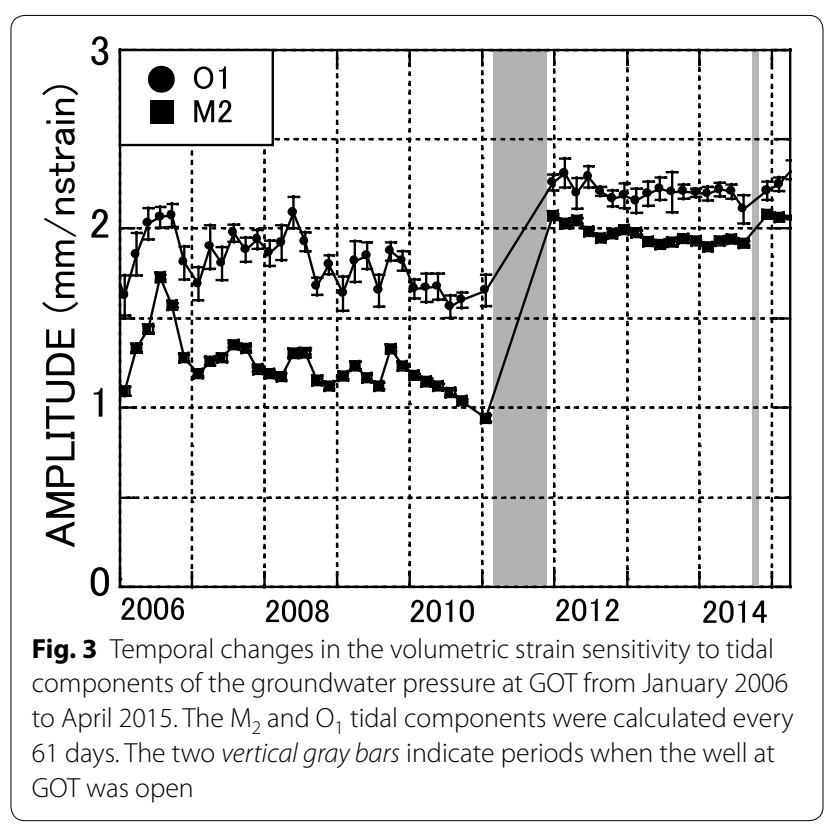


After this opening, the strain sensitivities also increased slightly. If we use the average of the sensitivities to the $\mathrm{O}_{1}$ and $\mathrm{M}_{2}$ components, the strain sensitivity of the groundwater pressure at GOT was around $1.6 \mathrm{~mm} /$ nstrain from 2006 to 2008 and $2.1 \mathrm{~mm} /$ nstrain from 2012 to 2014 .

Figure 4 shows all of the observation results for the period from January 2006 to April 2015. Shallow seismicity was observed under Mt. Ontake before and during the 2007 and 2014 eruptions. The baseline distance between HGW and MTK increased before the 2007 eruption, but it did not change before or after the 2014 eruption. The groundwater pressure at GOT decreased before the 2007 eruption, but, like the baseline length, it did not change before or after the 2014 eruption. During summer 2014, the groundwater pressure sensor sometimes malfunctioned and was eventually replaced, as explained later. The baseline distance between HGW and MTK increased and the groundwater pressure decreased almost simultaneously at the time of the 2011 off the Pacific coast of Tohoku earthquake (2011 Tohoku earthquake), which occurred on 11 March. During most of 2011, the GOT well was open for groundwater sampling, and no groundwater pressure data are available.

Figure 5 shows the observation results before and after the 2007 eruption of Mt. Ontake. Heavy precipitation caused the groundwater pressure at GOT to rise and fall. The changes in July 2006 and July 2007 are typical.

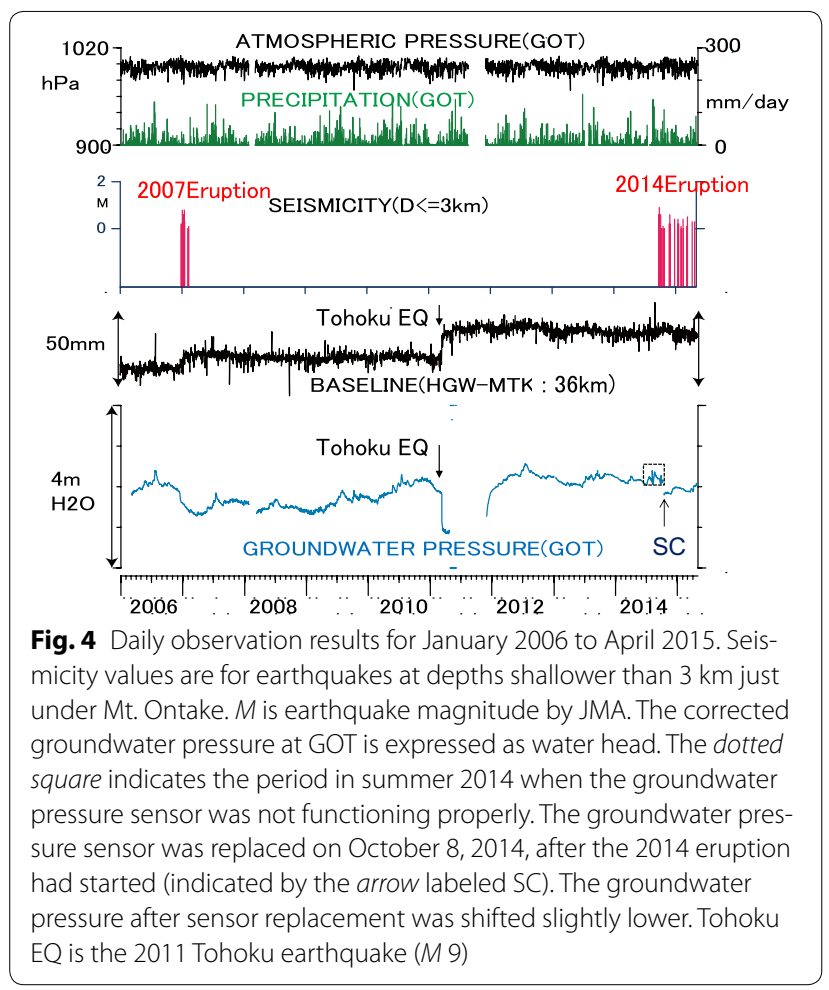

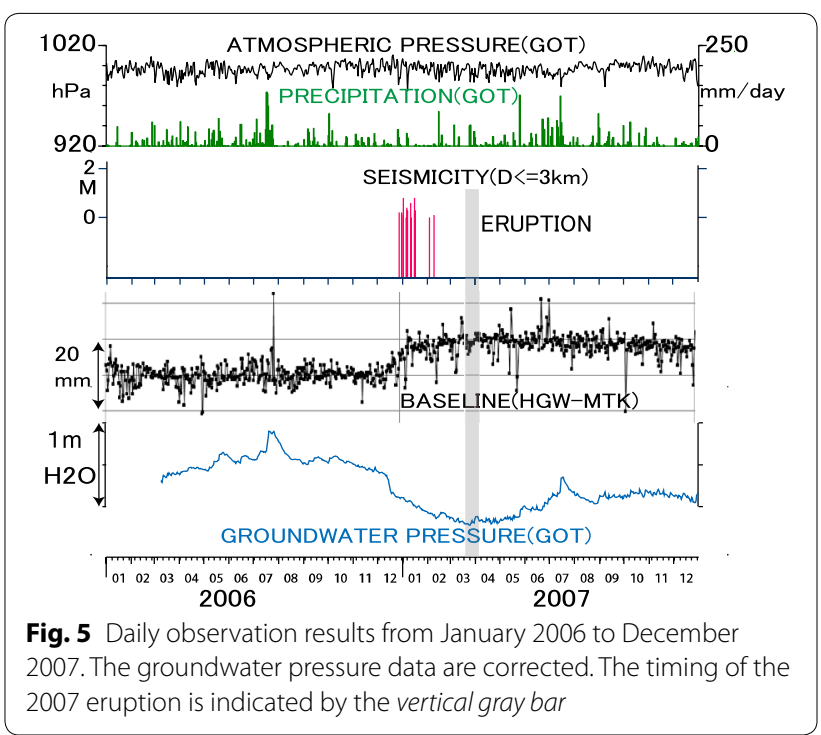

A few months before the 2007 eruption, relatively large crustal deformation, evidenced by a gradual increase (of about $10 \mathrm{~mm}$ ) in the HGW-MTK baseline distance across Mt. Ontake, was observed coinciding with volcano-seismic activity under Mt. Ontake (Nakamichi et al. 2009; Fig. 5). Because the total baseline distance is about $36 \mathrm{~km}$, the linear strain along the baseline was an extension of about 300 nstrain. About the same time as the start of the baseline increase on December 12, 2006, the groundwater pressure began to decrease at GOT. The pressure decrease, which was more rapid than the baseline increase, ended around 18 December, but the baseline increase continued at least until the beginning of January 2007. The groundwater pressure decrease from December 12 to December 18 in 2006 was about $20 \mathrm{~cm}$. Taking into account the volumetric strain sensitivity of the groundwater pressure, the $20 \mathrm{~cm}$ drop in groundwater pressure was equivalent to an increase in the volumetric strain at GOT of about 120 nstrain. During the period from December 12 to December 18, 2006, the baseline length increased by a few millimeters, an extension of about 100 nstrain. Therefore, these two independent strain observations agree well.

Beginning near the end of July 2014, many spikes in groundwater pressure were recorded (Fig. 6), which were attributed to problems with the groundwater pressure sensor. Therefore, the groundwater pressure sensor was replaced on October 8, 2014. Other than these spikes, no clear anomalous changes were detected in the groundwater pressure at GOT before the 2014 eruption. Figures 7 and 8 show the observation results at GOT just before and during the 2014 eruption together with the tilt changes at TNH of JMA. The observed groundwater 


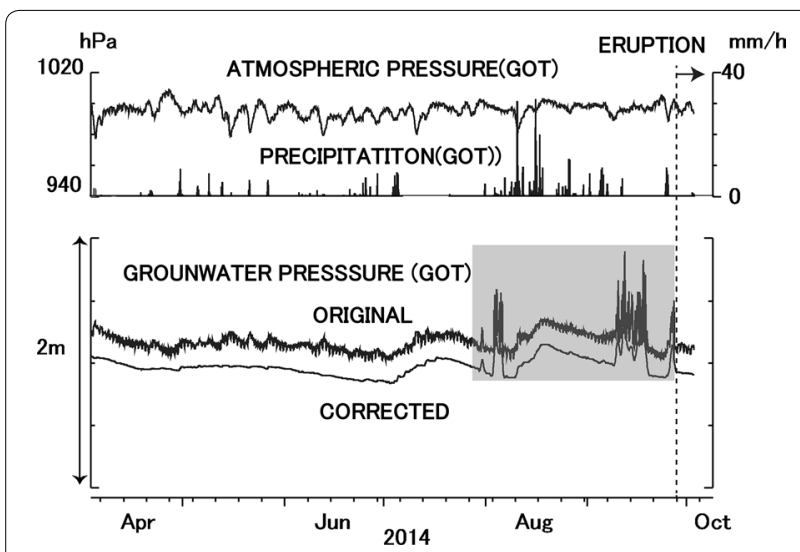

Fig. 6 Hourly atmospheric pressure, precipitation, and groundwater pressure at GOT from April 3 to October 8, 2014. Spike-like groundwater pressure changes were often recorded beginning near the end of July 2014 (gray shading)

pressure before the eruption also shows spikes caused by the malfunctioning sensor, but, fortunately, just a few hours before the eruption, normal values were observed. The tilt began to change at TNH several minutes before the eruption, and it changed again when the eruption began. However, no clear change in the groundwater pressure was detected before or during the eruption.

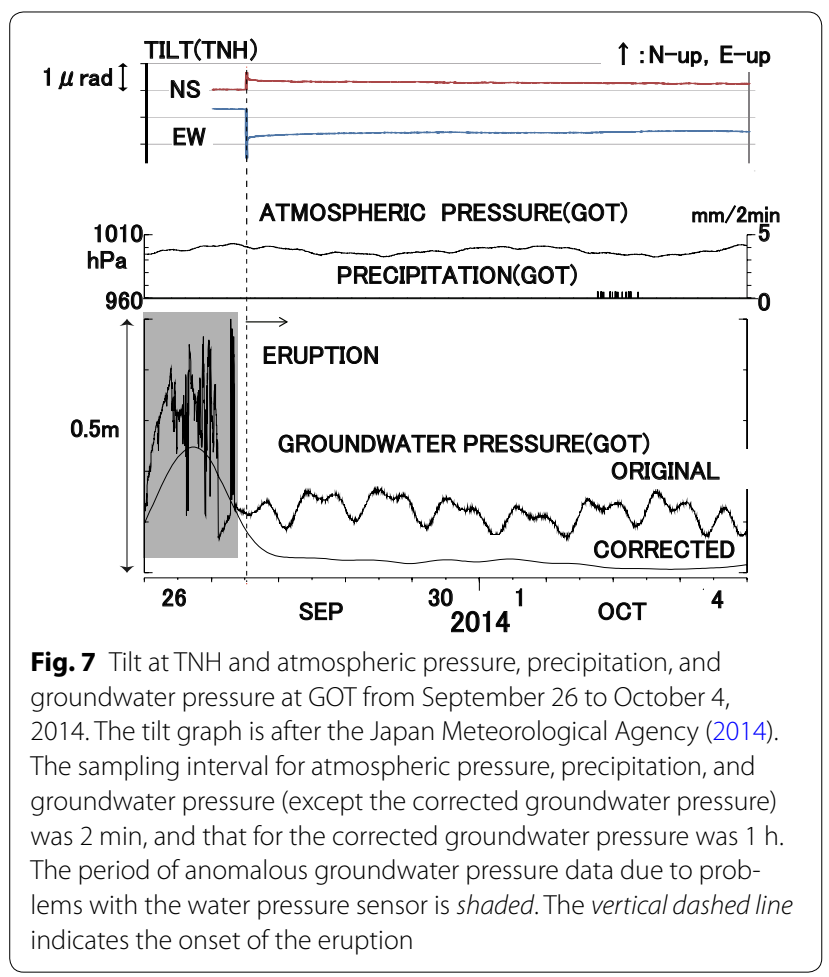

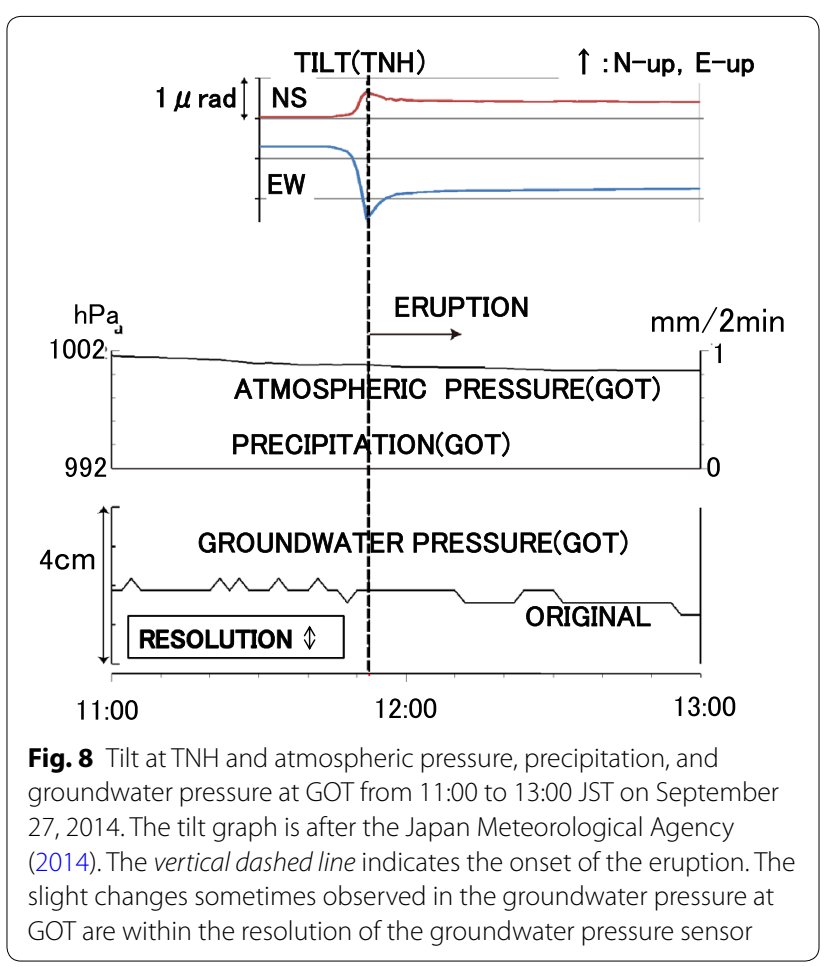

\section{Discussion and conclusions}

Nakamichi et al. (2009) suggested that, even though the eruption was phreatic, a magma intrusion occurred before the 2007 eruption. Figure 9 shows temporal strain changes in the six baselines between the four GNSS stations from October 2006 to May 2007. All of the baselines increased similarly before the 2007 eruption. These isotropic changes are consistent with the suggested magma intrusion. If magma intruded just under the summit of Mt. Ontake, as shown in Fig. 10a-2, it could have caused

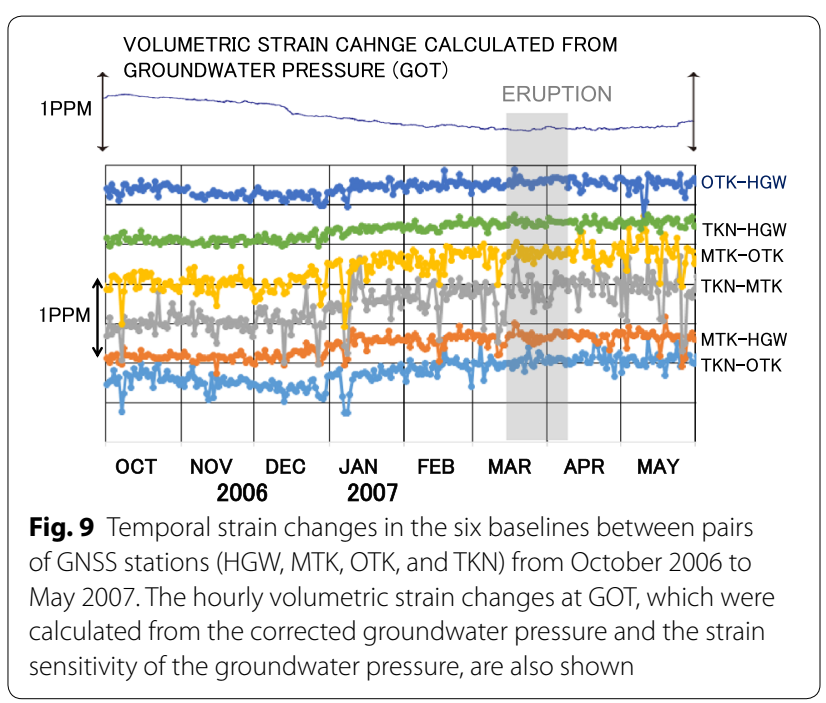




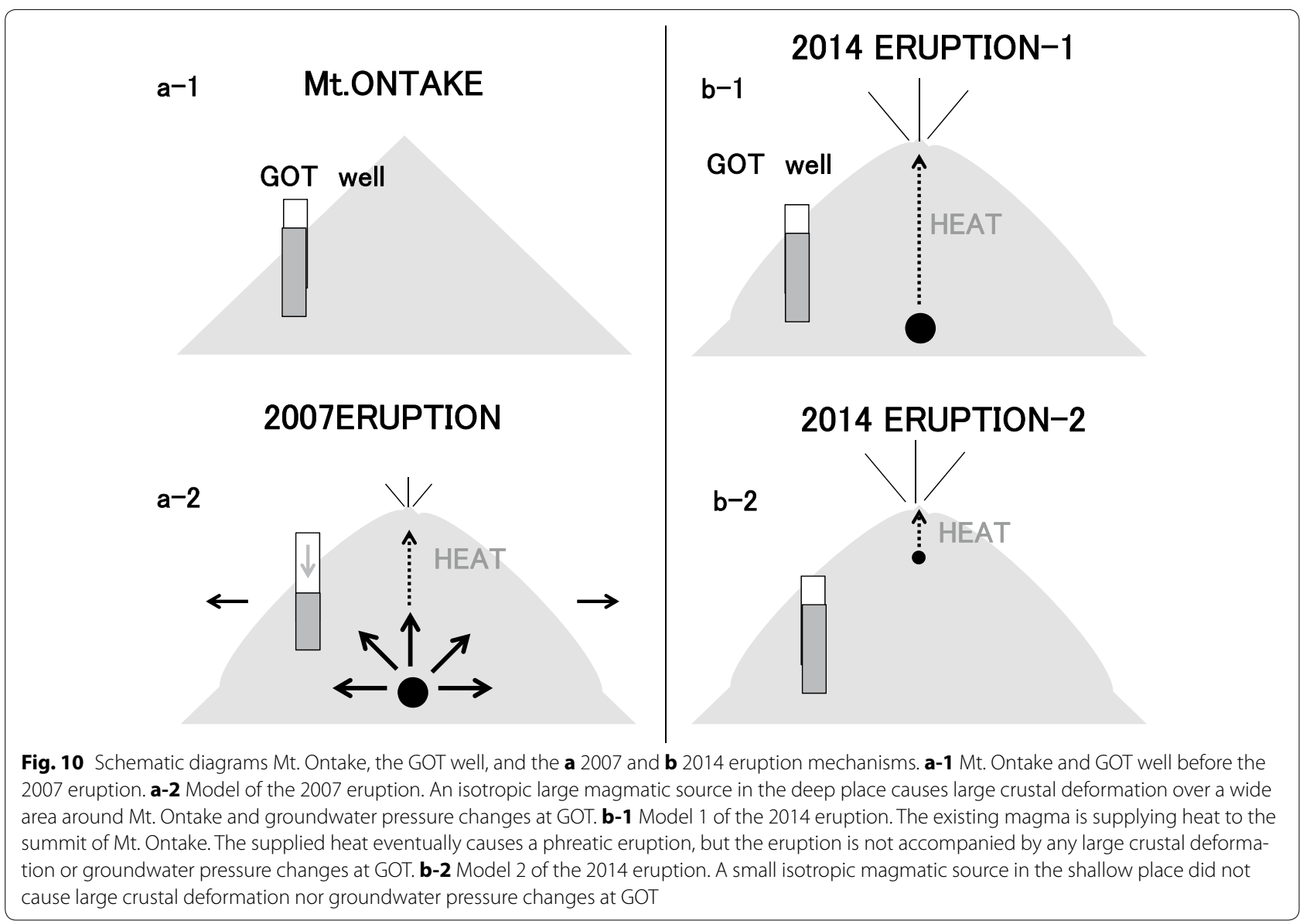

large, isotropic crustal deformation over a wide area before the eruption. Such crustal deformation could also account for the groundwater pressure changes at GOT. In contrast, if only heat transfer from an existing body of magma occurred (Fig. 10b-1), or if the intruded magma is small and stayed in the shallow place (Fig. 10b-2), neither large crustal deformation nor any groundwater pressure change at GOT would be observed before the eruption. According to Japan Meteorological Agency (2014), the volcanic ashes of the 2014 eruption mainly consist of hydrothermally altered rock fragments. Therefore, we think that the model of Fig. $10 \mathrm{~b}-1$ is more plausible although that of Fig. 10b-2 is also possible. Anyway we suggest that the first scenario (Fig. 10a-2) can explain the 2007 eruption and that the second scenario (Fig. 10b-1 or b-2) may explain the 2014 eruption. It is possible that the magma that intruded before the 2007 eruption remained in place subsequently and continued to supply heat to the summit of the Mt. Ontake, eventually causing the 2014 eruption. Kato et al. (2015) suggested the model of the 2014 eruption from the seismicity related to the 2014 eruption. Murase et al. (2016) also suggested the models for the 2007 and 2014 eruptions from precise leveling measurements. These models are almost consistent with our models.

To summarize, the Geological Survey of Japan, AIST, has been observing groundwater pressure at GOT since 1998. The groundwater pressure at GOT clearly dropped before the 2007 eruption, but it did not change before or after the 2014 eruption. These changes are consistent with crustal deformation observed by nearby GNSS stations. The difference between the 2007 and 2014 eruptions can be explained if a relatively large magma intruded before the 2007 eruption but no or a small magma intrusion occurred before the 2014 eruption.

\section{Authors' contributions}

NK carried out the data processing and analysis of the groundwater data and drafted the manuscript. TS carried out the groundwater observations and helped draft the manuscript. YK carried out the tidal analysis of the groundwater pressure and helped draft the manuscript. TO analyzed the GNSS data and helped draft the manuscript. All authors read and approved the final manuscript.

\section{Author details}

1 School of Environmental Science, The University of Shiga Prefecture, 2500, Hassaka-cho, Hikone-City, Shiga 522-8533, Japan. ${ }^{2}$ Geological Survey of Japan, AIST, C-7, 1-1-1, Higashi, Tsukuba-City, Ibaraki 305-8567, Japan. 


\section{Acknowledgements}

We thank the residents of Otaki village for their cooperation in this research. We are grateful to an anonymous reviewer for reviewing our manuscript and valuable comments.

\section{Competing interests}

The authors declare that they have no competing interests.

Received: 27 November 2015 Accepted: 26 February 2016

Published online: 17 March 2016

\section{References}

Cyranoski D (2014) Why Japan missed volcano's warning signs. Nature. doi:10.1038/nature.2014.16022

Earthquake Research Institute in the University of Tokyo (2014), http:// www.data.jma.go.jp/svd/vois/data/tokyo/STOCK/kaisetsu/CCPVE/ shiryo/130/130_no01.pdf. Accessed 8 Sept 2015

Geospatial Information Authority of Japan (2015) GNSS data providing service. http://terras.gsi.go.jp/. Accessed 22 Nov 2015

Imanishi K, Takeo M, Ellsworth WL, Ito H, Matsuzawa T, Kuwahara Y, lio Y, Horiuchi S, Ohmi S (2004) Source parameters and rupture velocities of microearthquakes in Western Nagano, Japan, determined using stopping phases. Bull Seismol Soc Am 94:1762-1780

Japan Meteorological Agency (2014) Rep. Coordin. Committee on prediction of volcanic eruption. http://www.data.jma.go.jp/svd/vois/data/tokyo/ STOCK/kaisetsu/CCPVE/shiryo/130/130_no01.pdf. Accessed 8 Sept 2015 (in Japanese)

Kato A, Terakawa T, Yamanaka Y, Maeda Y, Horikawa S, Matsuhiro K, Okuda $\mathrm{T}$ (2015) Preparatory and precursory processes leading up to the 2014 phreatic eruption of Mount Ontake, Japan. Earth, Planets Space 67:111. doi:10.1186/s40623-015-0288-x
Koizumi N, Kitagawai Y, Matsumoto N, Takahashi M, Sato T, Kamigaich O, Nakamura K (2004) Pre-seismic groundwater level changes induced by crustal deformations related to earthquake swarms off the east coast of Izu Peninsula, Japan. Geophys Res Lett 31:L10606. doi:10.1029/2004GL019557

Maeda Y, Kato A, Terakawa T, Yamanaka Y, Horikawa S, Matsuhiro K, Okuda T (2015) Source mechanism of a VLP event immediately before the 2014 eruption of Mt. Ontake, Japan. Earth, Planets Space 67:187. doi:10.1186/ s40623-015-0358-0

Matsumoto K, Sato T, Takanezawa T, Ooe M (2001) GOTIC2: a program for computation of oceanic tidal loading effect. J Geod. Soc Jpn 47:243-248

Murase M, Kimata F, Yamanaka Y, Horikawa S, Matsuhiro K, Matsushima T, Mori H, Ohkura T, Yoshikawa S, Miyajima R, Inoue H, Mishima T, Sonoda T, Uchida K, Yamamoto K, Nakamichi H (2016) Preparatory process preceding the 2014 eruption of Mount Ontake volcano, Japan: insights from precise leveling measurements. Earth, Planets Space 68:9. doi:10.1186/ s40623-016-0386-4

Nakamichi H, Kumagai H, Nakano M, Okubo M, Kimata F, Ito Y, Obara K (2009) Source mechanism of very-long-period event at Mt. Ontake, central Japan: response of a hydrothermal system to magma intrusion beneath the summit. J Volcanol Geotherm Res 187:167-177

Ogiso M, Matsubayashi H, Yamamoto T (2015) Descent of tremor source locations before the 2014 phreatic eruption of Ontake volcano, Japan. Earth, Planets Space 67:206. doi:10.1186/s40623-015-0376-y

Okada Y, Yamamoto E, Ohkubo T (2000) Coswarm and preswarm crustal deformation in the eastern Izu Peninsula, central Japan. J Geophys Res 105(B1):681-692

Sparks RSJ (2003) Forecasting volcanic eruptions. Earth Planet Sci Lett 210:1-15. doi:10.1016/S0012-821X(03)00124-9

Tamura Y, Sato T, Ooe M, Ishiguro M (1991) A procedure for tidal analysis with a Bayesian information criterion. Geophys J Int 104:507-516

Yamada N, Wakita K (1989) Geological map of Japan 1:200,000. lida, Geological Survey of Japan

\section{Submit your manuscript to a SpringerOpen ${ }^{\circ}$ journal and benefit from:}

- Convenient online submission

- Rigorous peer review

- Immediate publication on acceptance

- Open access: articles freely available online

- High visibility within the field

- Retaining the copyright to your article

Submit your next manuscript at $>$ springeropen.com 